\title{
(6) OPEN ACCESS \\ Associations between exemption and survival outcomes in the UK's primary care pay-for-performance programme: a retrospective cohort study
}

\author{
Evangelos Kontopantelis, ${ }^{1,2}$ David A Springate, ${ }^{1,3}$ Darren M Ashcroft, ${ }^{4}$ \\ Jose $M$ Valderas, ${ }^{5}$ Sabine $N$ van der Veer, ${ }^{2}$ David Reeves, ${ }^{1,3}$ \\ Bruce Guthrie, ${ }^{6}$ Tim Doran $^{7}$
}

- Additional material is published online only. To view please visit the journal online (http://dx.doi.org/10.1136/bmjgs2015-004602).

For numbered affiliations see end of article.

\section{Correspondence to}

Dr Evangelos Kontopantelis, Institute of Population Health, University of Manchester, 5th Floor, Williamson Building, Manchester M13 9PL, UK; e.kontopantelis@manchester. ac.uk

Received 14 July 2015 Revised 20 October 2015 Accepted 1 November 2015 Published Online First

1 December 2015

\section{SLinked}

- http://dx.doi.org/10.1136/ bmjqs-2015-005003

\section{CrossMark}

To cite: Kontopantelis $E$, Springate DA, Ashcroft DM, et al. BMJ Qual Saf 2016:25:657-670.

\begin{abstract}
Objectives The UK's Quality and Outcomes Framework permits practices to exempt patients from financially-incentivised performance targets. To better understand the determinants and consequences of being exempted from the framework, we investigated the associations between exception reporting, patient characteristics and mortality. We also quantified the proportion of exempted patients that met quality targets for a tracer condition (diabetes). Design Retrospective longitudinal study, using individual patient data from the Clinical Practice Research Datalink.
\end{abstract}

Setting 644 general practices, 2006/7 to 2011/12

Participants Patients registered with study practices for at least one year over the study period, with at least one condition of interest (2 460341 in total).

Main outcome measures Exception reporting rates by reason (clinical contraindication, patient dissent); all-cause mortality in year following exemption. Analyses with logistic and Cox proportional-hazards regressions, respectively. Results The odds of being exempted increased with age, deprivation and multimorbidity. Men were more likely to be exempted but this was largely attributable to higher prevalence of conditions with high exemption rates. Modest associations remained, with women more likely to be exempted due to clinical contraindication (OR $0.90,99 \% \mathrm{Cl} 0.88$ to 0.92 ) and men more likely to be exempted due to informed dissent (OR $1.08,99 \% \mathrm{Cl} 1.06$ to 1.10). More deprived areas (both for practice location and patient residence) were non-linearly associated with higher exception rates, after controlling for comorbidities and other covariates, with stronger associations for clinical contraindication. Compared with patients with a single condition, odds ratios for patients with two, three, or four or more conditions were respectively $4.28(99 \% \mathrm{Cl} 4.18$ to 4.38), 16.32 (99\% Cl 15.82 to 16.83 ) and 68.69 (99\% Cl 66.12 to 71.37 ) for contraindication, and 2.68 (99\% Cl 2.63 to 2.74), 4.02 (99\% Cl 3.91 to 4.13$)$ and $5.17(99 \% \mathrm{Cl} 5.00$ to 5.35$)$ for informed dissent. Exempted patients had a higher adjusted risk of death in the following year than non-exempted patients, regardless of whether this exemption was for contraindication (hazard ratio $1.37,99 \% \mathrm{Cl} 1.33$ to 1.40$)$ or for informed dissent $(1.20,99 \% \mathrm{Cl} 1.17$ to 1.24$)$. On average, quality standards were met for $48 \%$ of exempted patients in the diabetes domain, but there was wide variation across indicators (ranging from 8 to $80 \%$ ).

Conclusions Older, multimorbid and more deprived patients are more likely to be exempted from the scheme. Exception reported patients are more likely to die in the following year, whether they are exempted by the practice for a contraindication or by themselves through informed dissent. Further research is needed to understand the relationship between exception reporting and patient outcomes.

\section{INTRODUCTION}

Pay-for-performance programmes aim to improve patient care by providing financial incentives to providers for meeting quality targets. Major national schemes have been introduced in several countries over the past decade, including the 
Quality and Outcomes Framework (QOF) in the UK, ${ }^{1}$ the Hospital Value-Based Purchasing Program ${ }^{2}$ and the Medicare Physician Quality Reporting System ${ }^{3}$ in the USA, and the Practice Incentives Program in Australia. ${ }^{4}$ Schemes implemented to date have had mixed success in improving processes of $\mathrm{care}^{5-7}$ and there is conflicting evidence for their impact on patient outcomes. ${ }^{8-13}$ Optimal programme designs remain elusive. One of the main challenges is to ensure that targets applied to whole populations are appropriate for individual patients, so that patient autonomy is respected and unnecessary investigations and treatments are avoided for those who will not benefit.

The UK's QOF programme provides incentives to family practices for meeting a wide range of clinical, organisational and patient experience targets. ${ }^{1}$ Data on performance are extracted from practices' clinical computing systems and are collated in a national database (QMAS) and assessed at the end of each financial year. The scheme includes provisions for practices to exempt (or 'exception report') patients they deem inappropriate from single, multiple or all incentivised targets (box 1). Patients who refuse investigations and treatments can also be exempted, provided that the practice has discussed the reasons directly with the patient. Practices are not financially penalised if they miss quality targets for exempted patients, since these patients are not included in the annual calculation of quality achievement. The most common reasons for exception reporting are logistical (recent registration or diagnosis-41\%), followed by informed dissent $(30 \%)$ and clinical contraindication or unsuitability $(26 \%) .^{14}$

If used appropriately, exception reporting is a potentially effective tool for introducing some flexibility into national indicator sets. It allows doctors to exercise clinical judgement in the pursuit of quality targets and to tailor care according to individual circumstances. However, inappropriate use of exception reporting can undermine pay-for-performance programmes, potentially enabling practices to claim large financial rewards without providing the recommended level of care. ${ }^{15} 16$ Initially, practices exempted relatively few patients (median 5.3\%, IQR 4.0\%-6.9\% in $2005 / 2006),{ }^{17}$ but exemption rates have increased as quality targets have been made more challenging, ${ }^{18} 19$ which might reflect more accurate recording of genuine exemptions or gaming to maximise income. $^{1620}$

Studies of exception reporting have been limited in two respects. ${ }^{15}{ }^{17}$ First, the levels of exception reporting are routinely reported at the practice level, and it is therefore not possible to examine the relationships between exception reporting, patient characteristics (such as age, sex and multimorbidity) and outcomes. Previous investigations have found that overall rates of exceptions under the QOF have been low, but there is wide variation between quality indicators (ranging from zero to $24 \%$ ) and between practices. ${ }^{14}$ This has raised concerns that particular groups of patients-for example, those living in more deprived areas, with particular conditions, or with multimorbidity-are more likely to be exception reported and, as a result, may have poorer health outcomes. Understanding these issues requires patient-level analysis. To date, patient-level analyses have been restricted to local areas and specific conditions, and have found that patients living in deprived areas, from ethnic minorities and with multimorbidity are more likely to be exception reported and are subsequently less likely to achieve treatment goals. ${ }^{21}$

Second, if a patient who has been exception reported subsequently meets the target (eg, if they initially refuse to have their blood pressure measured but later attend for monitoring or have blood pressure measured as part of other care) the exception report is overridden. Although a record of the original exception report remains on the practice's clinical computing system, the patient is not counted as an exception on the national QMAS database. This creates two classes of exempted patients: (1) those for whom the quality standards were not met, the numbers of which can be derived and are routinely reported on the QMAS database ${ }^{22}$ and (2) those for whom the standards were met, the numbers of which cannot be derived from national data. Thus, the total percentage of patients who receive an exception code is higher than the nationally reported rate, which does not include patients for whom the exception report was subsequently overridden. However, the levels of both types of exemption are informative. For example, a high ratio of 'met' to 'unmet' clinical contraindication exemptions might suggest that the exception reporting provision is being applied too liberally in the first instance. For informed dissent, a high rate of 'met' exception reports might reflect dissenting patients reconsidering their original decision, either autonomously or under pressure from practices.

In this study, we used individual patient-level data to investigate: (1) patterns of exception reporting; (2) patient and practice predictors of exception reporting; (3) the associations between different types of exception reporting and mortality and (4) rates of both 'met' and 'unmet' exceptions for patients with a tracer condition (diabetes).

\section{METHODS}

Guidance for exception reporting is produced annually by NHE Employers, ${ }^{23}$ and details of the recording of exceptions by practices have been previously described. ${ }^{14}$ Exemptions are applied on an individualpatient basis using one of nine permitted reasons (box 1). However, practice clinical computing systems use a limited set of exception codes, and some reasons are conflated in the electronic patient record. For the 
Box 1 Permissible reasons for exception reporting patients

Logistical

- The patient is newly diagnosed or recently registered with the practice*

- The investigative or secondary care service is unavailable to the practice

Clinical contraindication or unsuitability

- The patient has an allergy, another contraindication or has experienced an adverse reaction to the specified medication

- The patient has not tolerated medication

- The patient is on the maximum tolerated dose of medication, but levels remain suboptimal

- The patient has a supervening condition that makes treatment clinically inappropriate

- The patient is not appropriate due to particular circumstances, for example terminal illness or extreme frailty $\dagger$

\section{Informed dissent}

- The patient refuses to attendt

- The patient does not agree to investigation or treatment $\ddagger$

*Within 3 months in the case of measurement indicators (eg, measurement of blood pressure) and 9 months in the case of treatment and outcomes indicators (eg, control of blood pressure within target levels). The patient is excluded from all relevant indicators.

tPatient is excluded for the whole clinical domain (eg, all diabetes indicators).

¥Patient is excluded for this activity across all clinical domains (eg, measurement of blood pressure).

purposes of this study, exception reports were categorised under broad categories as: (1) logistical; (2) clinical contraindication or unsuitability; (3) informed dissent and (4) unknown reason. The latter group consists of patients who have been exempted from whole clinical domains, where the specific reason is not recorded. We did not examine logistical exemptions in our analyses, as these mainly relate to patients registered or diagnosed towards the end of each year.

\section{Data sources}

We extracted data from the Clinical Practice Research Datalink (CPRD), a database of individual patient records drawn from family practices in the UK using the Vision clinical computer system (used in approximately a fifth of all practices ${ }^{24}$ ). Available data include patient diagnoses, management and deaths. In July 2012, data were available for 645 practices and 13772992 patients. Data were linked to Office of National Statistics (ONS) data, allowing measurement of area deprivation (using the Index of Deprivation ${ }^{25}$ ) at the practice location. More detailed information on area deprivation measured at the patient's location ${ }^{26}$ and on deaths verified by ONS were only available for a subgroup of 357 practices that had agreed to the additional linkages (covering approximately $60 \%$ of patients).

\section{Study design: retrospective cohort}

There was a major revision of the QOF scheme in 2006, therefore to ensure consistency in our longitudinal analyses we limited the study period to years 38 of the scheme (1 April 2006 to 31 March 2012). Practice performance on the QOF is measured across financial years and we divided the study period into six financial years (1 April to 31 March the following year). Within each year, we identified practices that reliably contributed data for the whole year. ${ }^{27}$ Within each practice and study year, we selected patients registered with the practice for the full year and from these we identified patients with at least one condition of interest, at any point in time up to the end of the respective year.

Conditions of interest were those incentivised in the QOF from 2006 onwards: atrial fibrillation, asthma, hypertension, cancer, coronary heart disease, heart failure, chronic kidney disease, chronic obstructive pulmonary disease, dementia, depression, diabetes, epilepsy, learning disability, severe mental health, stroke and hypothyroidism. We excluded clinical domains that were not a condition (eg, palliative care), were concerned only with maintenance of a register (eg, obesity) or that were introduced in later years (eg, osteoporosis). All codes used in the study are available at http://www.clinicalcodes.org. ${ }^{28}$

\section{Datasets}

Using R V.3.1.1, ${ }^{29}$ we generated three datasets with which we aimed to answer our main research questions. Dataset \#1 included yearly aggregated exception reporting information for patients with at least one of the conditions of interest. Dataset \#2 contained all recorded exception information for patients in dataset \#1: Read exception code, type of exception, exception date and QOF indicators to which the exception applied. Dataset \#3 focused on patients with diabetes aged 18 or over: diabetes diagnosis date, information on eligibility, achievement and exceptions for 15 clinical indicators that were included in the QOF diabetes domain for most or all of the study period. Full details are provided in the online supplementary appendix.

\section{Analyses}

Analyses were undertaken in Stata V.13.1, and an $\alpha$ level of $1 \%$ was used throughout. ${ }^{30}$ However, statistical significance is not very informative in analyses of datasets of this size and we focus on the clinical significance of the effect sizes rather than $p$ values. ${ }^{31}$ 
Using dataset \#1, we descriptively examined the characteristics of patients who are exception reported and used regression modelling of practices with linked ONS data to investigate predictors of exception reporting and examined whether exemption is associated with mortality. Longitudinal random-effects logistic regression models were used to assess the effect of year, gender, age, the presence of each of the 16 conditions of interest (as binary variables), practice list size, region and deprivation on the presence of at least one relevant exception code. Alternative models included the number of relevant conditions (one, two, three, four or more) as predictors, in place of the individual conditions.

Proportional-hazards survival models with yearly time-windows were used to examine the associations between patient mortality and age, gender, smoking status (current, ex, never smoked, missing), area deprivation at the patient's location, each of the 16 conditions of interest, practice list size, area deprivation at the practice location and exception reports. Recorded information in each year was used to model survival or death in the subsequent year; that is, 2007/ 2008 deaths were predicted using 2006/2007 data, etc, up until 2011/2012 deaths predicted by 2010/ 2011 data. We introduced time-varying covariates, when needed, to ensure the proportional-hazard assumption stood. The relationship between exception reporting and mortality was investigated in two separate survival models. In the first, types of exception reporting (clinical contraindication, informed dissent and reason unknown) were included as separate predictors. In the second, all three reasons were aggregated into a single predictor. As sensitivity analyses, we calculated propensity scores (for all reasons, contraindication and informed dissent) as an alternative means of controlling for the role of the covariates on the probability of being exception reported.

We used dataset \#2 to investigate the frequency of all relevant exception codes used over time. We aggregated the data at the practice level to calculate the number of exception codes per 1000 patients in each practice. Dataset \#3 was used to descriptively provide insight on exception reported patients for which the relevant quality indicator (or indicators) was met, for all indicators in the diabetes domain and each financial year. Due to the complexity of fully mapping a QOF clinical domain in a primary care database, we were only able to perform this analysis for one condition. We selected diabetes as it has high prevalence and the greatest range of QOF indicators.

\section{RESULTS}

Between 2006/2007 and 2011/2012, 644 of the 645 CPRD practices were active, and a total of 2460341 patients were identified with at least one of the 16 conditions of interest (the respective figures for the ONS linked data were 1470461 patients and 357 practices). In 2006/2007, 569 practices were active (ie, provided data) with a total registered population of 5321351 patients, of which 1602366 patients $(30.1 \%)$ had at least one of the examined QOF conditions. In 2011/2012, 499 practices were active with a total population of 5069748 patients, of whom 1486578 (29.3\%) had at least one of the conditions.

Exemption rates over time are provided in table 1. Additional information on the characteristics of nonexempted and exempted patients, by exception reporting category, is provided in online supplementary appendix table A1. Prevalence rates for the modelled conditions are provided in online supplementary appendix table A2. The percentage of patients with an examined condition who had at least one exception reporting code remained relatively stable over the study period at $18.8 \%-19.9 \%$. In 2011/2012, $12.4 \%$ of patients received at least one clinical contraindication code and $9.0 \%$ received an informed dissent code (figure 1). In 2011/2012, exception reporting rates for any reason (excluding logistical exceptions) ranged from $17.1 \%$ in South-Central England to $25.5 \%$ in Scotland. Rates increased with increasing area deprivation, both for practice location $18.1 \%$ in the least deprived quintile in 2011/2012 and 21.4\% in the most deprived) and patient location (17.3\% and $19.8 \%$, respectively). On average, exempted patients were older than non-exempted patients (mean age 61.6 and 54.5, respectively, in 2011/2012) and men were exception reported more often than women (21.2\% compared with $18.8 \%)$. Patients who died were more likely to have been exception reported in the previous year (41.4\% for 2010/2011) than those who remained alive (19.5\%). Percentages of patients receiving at least one exception code varied across conditions from $16.5 \%$ (in 2011/2012) for depression and learning disability to $46.2 \%$ for heart failure.

The most commonly reported specific reason for exception reporting was 'influenza vaccination declined', making up approximately $15 \%$ of all nonlogistical exceptions within a year (see online supplementary appendix table A4). Other common reasons were 'asthma resolved' (5.4\%), 'informed dissent for asthma indicators' (4.2\%) and 'depression resolved' (3.5\%).

\section{Predictors of exception reporting}

Use of exception reporting increased over time, especially for informed dissent (table 2). In our regression models, the odds of being exception reported increased with age. Men were more likely to be exempted than women for informed dissent $(\mathrm{OR}=1.08,99 \% \mathrm{CI} 1.06$ to 1.10$)$, but less likely for contraindications $(\mathrm{OR}=0.90,99 \%$ CI 0.88 to 0.92$)$. The odds of being exempted varied across clinical domains, at least partly reflecting opportunities to be exempted (odds of exception reporting for any reason 
Table 1 Rates of exception reporting and characteristics of included patients, 2006/2007 to 2011/2012

\begin{tabular}{|c|c|c|c|c|c|c|}
\hline & $2006 / 2007$ & $2007 / 2008$ & $2008 / 2009$ & $2009 / 2010$ & 2010/2011 & $2011 / 2012$ \\
\hline \multicolumn{7}{|l|}{ Populations-all practices } \\
\hline No of practices & 569 & 566 & 565 & 556 & 534 & 499 \\
\hline Total list size & 5321351 & 5370801 & 5449547 & 5432224 & 5301520 & 5069748 \\
\hline Patients with at least one of the 16 conditions (\%) & 30.1 & 30.0 & 30.1 & 30.0 & 29.8 & 29.3 \\
\hline \multicolumn{7}{|l|}{ Populations—ONS linkage } \\
\hline No of practices & 333 & 336 & 335 & 332 & 313 & 289 \\
\hline Total list size & 3257681 & 3362641 & 3408043 & 3415997 & 3271321 & 3157801 \\
\hline Patients with at least one of the 16 conditions (\%) & 29.5 & 29.3 & 29.3 & 29.1 & 29.0 & 28.4 \\
\hline \multicolumn{7}{|l|}{ Exceptions: clinical contraindication } \\
\hline Patients with one or more (\%) & 12.6 & 12.3 & 11.9 & 12.3 & 12.4 & 12.4 \\
\hline Patients with more than one (\%) & 3.7 & 3.8 & 3.4 & 3.3 & 3.2 & 3.2 \\
\hline \multicolumn{7}{|l|}{ Exceptions: informed dissent } \\
\hline Patients with one or more (\%) & 8.0 & 8.6 & 8.3 & 8.6 & 9.2 & 9.0 \\
\hline Patients with more than one (\%) & 1.7 & 2.1 & 2.0 & 1.9 & 2.0 & 2.0 \\
\hline \multicolumn{7}{|l|}{ Exceptions: reason unknown (general) } \\
\hline Patients with one or more (\%) & 0.2 & 0.2 & 0.2 & 0.1 & 0.1 & 0.1 \\
\hline Patients with more than one (\%) & 0.0 & 0.0 & 0.0 & 0.0 & 0.0 & 0.0 \\
\hline \multicolumn{7}{|l|}{ Exceptions: all reasons* } \\
\hline Patients with one or more (\%) & 19.1 & 19.3 & 18.8 & 19.3 & 19.9 & 19.8 \\
\hline Patients with more than one (\%) & 6.1 & 6.5 & 5.9 & 5.8 & 6.0 & 5.8 \\
\hline \multicolumn{7}{|c|}{ Exceptions: clinical contraindication AND informed dissent } \\
\hline Patients with one or more (\%) & 1.6 & 1.7 & 1.6 & 1.6 & 1.7 & 1.6 \\
\hline Patients with more than one (\%) & 0.2 & 0.2 & 0.2 & 0.2 & 0.2 & 0.2 \\
\hline \multicolumn{7}{|c|}{ By region: percentage of patients with one or more exception (all reasons*) } \\
\hline \multicolumn{7}{|c|}{ English regions } \\
\hline North East & 18.2 & 19.0 & 17.3 & 19.0 & 19.0 & 18.7 \\
\hline North West & 19.6 & 19.7 & 19.1 & 19.6 & 20.0 & 19.5 \\
\hline Yorkshire and Humber & 17.8 & 18.6 & 18.1 & 18.3 & 18.7 & 20.5 \\
\hline East Midlands & 21.9 & 19.6 & 22.2 & 20.1 & 20.5 & 20.7 \\
\hline West Midlands & 15.8 & 16.6 & 16.3 & 16.8 & 18.4 & 18.6 \\
\hline East England & 17.8 & 18.7 & 18.3 & 18.8 & 19.3 & 18.6 \\
\hline South West & 19.6 & 20.8 & 20.7 & 21.3 & 22.5 & 23.3 \\
\hline South Central & 17.0 & 16.8 & 16.7 & 17.4 & 18.0 & 17.1 \\
\hline London & 18.8 & 17.8 & 16.4 & 17.1 & 17.8 & 16.8 \\
\hline South East & 16.9 & 16.4 & 15.4 & 17.0 & 17.6 & 17.1 \\
\hline \multicolumn{7}{|l|}{ Country aggregates } \\
\hline England & 18.2 & 18.3 & 17.8 & 18.4 & 19.1 & 18.7 \\
\hline Northern Ireland & 19.3 & 20.8 & 20.0 & 18.9 & 17.3 & 18.4 \\
\hline Scotland & 22.2 & 21.8 & 22.0 & 23.3 & 24.3 & 25.5 \\
\hline Wales & 23.5 & 24.3 & 22.7 & 22.7 & 23.1 & 22.7 \\
\hline \multicolumn{7}{|c|}{ By practice area deprivation quintile: percentage of patients with one or more exception (all reasons*) } \\
\hline 1 (least deprived) & 18.0 & 18.0 & 17.3 & 17.3 & 18.3 & 18.1 \\
\hline 2 & 18.0 & 19.0 & 18.6 & 18.9 & 19.6 & 20.1 \\
\hline 3 & 19.9 & 19.7 & 18.8 & 19.5 & 20.4 & 20.4 \\
\hline 4 & 19.9 & 19.6 & 19.4 & 19.9 & 20.1 & 19.1 \\
\hline 5 & 19.6 & 20.0 & 19.5 & 20.8 & 21.4 & 21.4 \\
\hline \multicolumn{7}{|c|}{ By patient area deprivation quintile: percentage of patients with one or more exception (all reasons ${ }^{*}$ ) $\dagger$} \\
\hline 1 (least deprived) & 16.6 & 16.8 & 16.2 & 16.6 & 17.8 & 17.3 \\
\hline 2 & 18.0 & 18.1 & 17.8 & 18.1 & 19.1 & 18.9 \\
\hline 3 & 18.5 & 18.6 & 18.3 & 18.8 & 19.9 & 19.8 \\
\hline 4 & 19.0 & 18.9 & 18.4 & 18.9 & 19.6 & 19.1 \\
\hline 5 & 19.2 & 19.1 & 18.8 & 19.9 & 20.1 & 19.7 \\
\hline
\end{tabular}


Table 1 Continued

\begin{tabular}{|c|c|c|c|c|c|c|}
\hline & $2006 / 2007$ & $2007 / 2008$ & $2008 / 2009$ & $2009 / 2010$ & $2010 / 2011$ & $2011 / 2012$ \\
\hline \multicolumn{7}{|c|}{ By sex: percentage of patients with one or more exception (all reasons*) } \\
\hline Female & 17.9 & 18.0 & 17.6 & 18.0 & 18.7 & 18.8 \\
\hline Male & 20.7 & 20.9 & 20.3 & 21.0 & 21.5 & 21.2 \\
\hline \multicolumn{7}{|c|}{ By smoking status: percentage of patients with one or more exception (all reasons*) } \\
\hline Never & 17.3 & 17.4 & 16.8 & 17.1 & 17.8 & 17.6 \\
\hline Ex-smoker & 21.3 & 21.6 & 20.9 & 21.4 & 21.9 & 21.6 \\
\hline Smoker & 17.8 & 17.4 & 17.1 & 18.0 & 18.7 & 19.1 \\
\hline Missing & 11.2 & 10.5 & 9.8 & 9.8 & 10.2 & 10.0 \\
\hline \multicolumn{7}{|c|}{ By death in next year: percentage of patients with one or more exception (all reasons*) } \\
\hline Alive & 18.6 & 18.7 & 18.3 & 18.9 & 19.5 & . \\
\hline Dead & 41.8 & 42.0 & 40.5 & 41.0 & 41.4 & . \\
\hline \multicolumn{7}{|c|}{ By condition: percentage prevalence rates in patients with one or more exception (all reasons*) } \\
\hline Atrial fibrillation & 40.5 & 42.4 & 41.0 & 41.3 & 41.4 & 40.7 \\
\hline Asthma & 26.5 & 25.7 & 25.4 & 25.9 & 26.7 & 26.8 \\
\hline Hypertension & 23.8 & 24.7 & 23.9 & 24.5 & 25.0 & 24.5 \\
\hline Cancer & 19.8 & 20.3 & 19.6 & 19.9 & 20.4 & 19.8 \\
\hline Coronary heart disease & 47.2 & 47.8 & 45.6 & 45.8 & 45.7 & 44.3 \\
\hline Heart failure & 47.8 & 47.9 & 47.0 & 49.7 & 48.4 & 46.2 \\
\hline Chronic kidney disease & 35.8 & 37.0 & 34.4 & 34.5 & 34.4 & 33.3 \\
\hline COPD & 45.7 & 46.0 & 44.8 & 46.6 & 45.8 & 43.5 \\
\hline Dementia & 38.5 & 38.8 & 36.8 & 37.5 & 38.3 & 36.7 \\
\hline Depression & 14.3 & 14.1 & 14.0 & 14.9 & 16.0 & 16.5 \\
\hline Diabetes mellitus & 36.7 & 38.3 & 36.8 & 38.6 & 38.6 & 36.7 \\
\hline Epilepsy & 28.9 & 28.8 & 28.4 & 27.8 & 28.5 & 30.2 \\
\hline Learning disability & 15.7 & 15.9 & 15.4 & 14.9 & 15.8 & 16.4 \\
\hline Severe mental illness & 26.3 & 26.9 & 25.7 & 26.9 & 27.2 & 28.9 \\
\hline Stroke & 42.0 & 42.1 & 40.1 & 40.1 & 40.6 & 39.1 \\
\hline Hypothyroidism & 19.3 & 19.7 & 18.9 & 19.2 & 19.7 & 19.4 \\
\hline \multicolumn{7}{|c|}{ Means (SDs) for patients with one or more exceptions (all reasons*) } \\
\hline Age $\ddagger$ & $61.4(20.4)$ & $62.1(19.9)$ & $61.9(19.8)$ & $61.8(19.6)$ & $61.9(19.5)$ & $61.6(19.3)$ \\
\hline No of morbidities $\ddagger$ & $2.3(1.4)$ & $2.3(1.4)$ & $2.3(1.4)$ & $2.3(1.4)$ & $2.3(1.4)$ & $2.3(1.4)$ \\
\hline BMI§ & $28.4(6.4)$ & $28.6(6.6)$ & $28.7(6.7)$ & $28.9(6.8)$ & $28.9(6.6)$ & $29.0(6.7)$ \\
\hline BMI missing (\%) & 50.0 & 51.2 & 50.9 & 50.8 & 50.7 & 50.2 \\
\hline \multicolumn{7}{|c|}{ Means (SDs) for patients without an exception } \\
\hline Age $\ddagger$ & $52.9(19.7)$ & $53.0(19.5)$ & $53.4(19.5)$ & $53.6(19.4)$ & $54.0(19.2)$ & $54.5(19.1)$ \\
\hline No of morbidities $\ddagger$ & $1.5(0.9)$ & $1.5(0.9)$ & $1.5(0.9)$ & $1.5(0.9)$ & $1.6(0.9)$ & $1.6(0.9)$ \\
\hline BMI§ & $28.4(6.4)$ & $28.5(6.5)$ & $28.7(6.6)$ & $28.8(6.7)$ & $28.9(6.6)$ & $28.9(6.6)$ \\
\hline BMI missing (\%) & 60.6 & 62.7 & 61.3 & 61.2 & 60.6 & 59.5 \\
\hline
\end{tabular}

${ }^{*}$ Clinical contraindication, informed dissent or reason unknown. Logistical exceptions were not included in analyses.

†Available for ONS linked patients only.

¥Data were complete for age and number of morbidities.

$\S$ Partially imputed using the mibmi algorithm.

$\mathrm{BMI}$, body mass index; COPD, chronic obstructive pulmonary disease; ONS, Office of National Statistics.

was positively correlated with the number of indicators in the domain, Spearman's rho $=0.73$ for 2011/ 2012). The highest odds of a contraindication exception was observed for patients with coronary heart disease $(\mathrm{OR}=23.71,99 \%$ CI 22.87 to 24.58$)$ and the highest informed dissent odds for patients with diabetes $(\mathrm{OR}=5.38,99 \%$ CI 5.25 to 5.52), compared with patients without each of the conditions, respectively (but with one of the investigated QOF conditions, in order for exceptions to be relevant). The odds of being exception reported for a contraindication increased with deprivation in the area the patient lived in, with the largest difference between the most and least affluent areas $(\mathrm{OR}=1.29$, 99\% CI 1.24 to 1.35 ). For informed dissent, however, the biggest differences were observed between the third and fourth quintile and the first (most affluent) quintile. When area deprivation was measured at the practice location, the odds of being exempted for a contraindication were highest for the third quintile $(\mathrm{OR}=1.84,99 \%$ CI 1.76 to 1.92$)$ and the odds of being exception reported for informed dissent were 


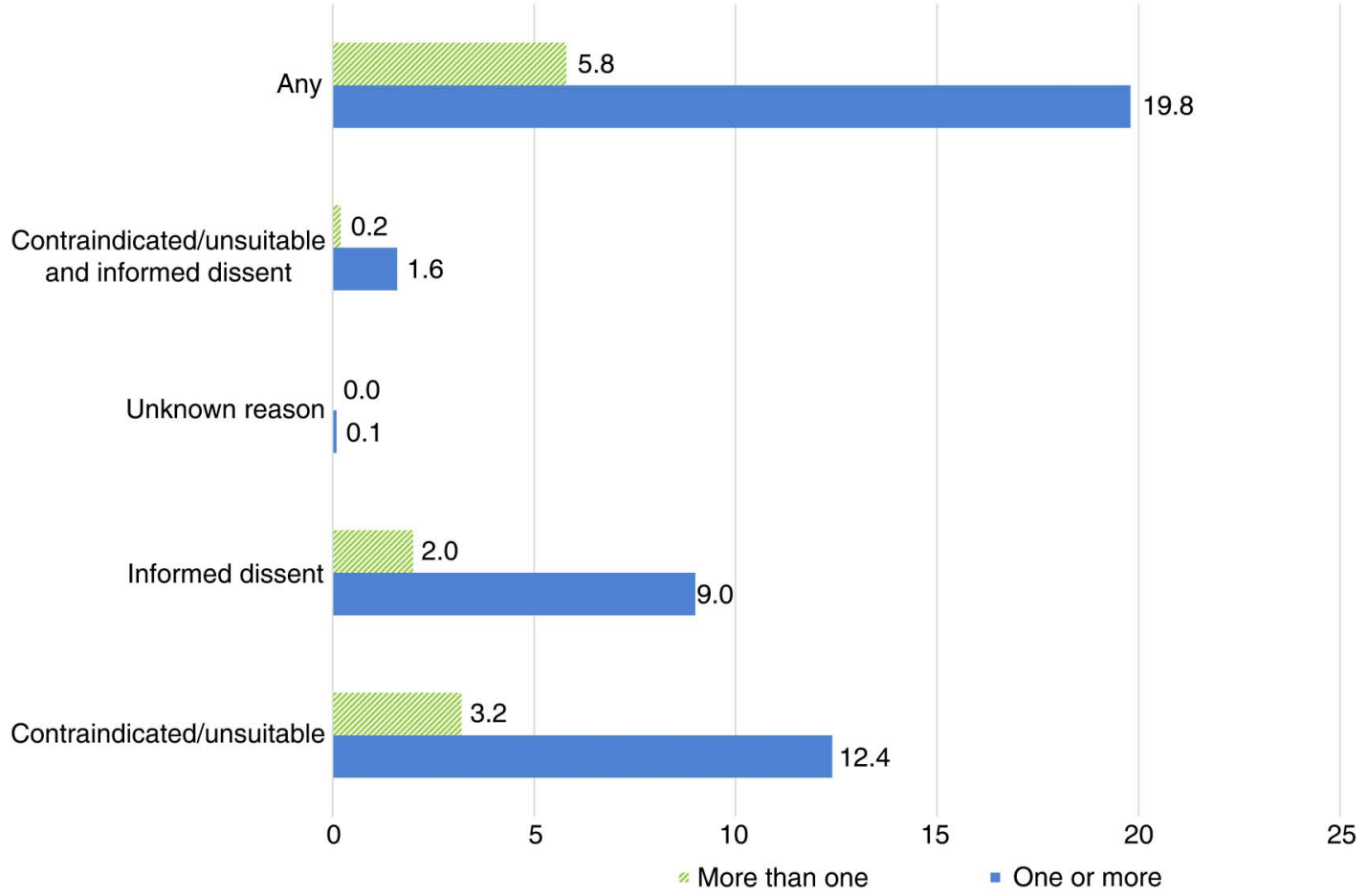

Figure 1 Exception reporting rates by reason for 2011/2012, the last year of the study.

*Unknown relates to global exceptions applied to the entire domain, where a specific reason for exclusion has not been recorded.

highest for the 5th (most deprived) quintile $(\mathrm{OR}=1.19,99 \%$ CI 1.15 to 1.24$)$.

In the models where we used the number of morbidities as predictor, rather than the individual conditions, the number of morbidities was a very strong predictor of both clinical contraindication and informed dissent exemptions (see online supplementary appendix table A5). Compared with patients with a single condition, ORs for patients with two, three or four or more conditions were, respectively 4.28 (99\% CI 4.18 to 4.38$), 16.32$ (99\% CI 15.82 to $16.83)$ and 68.69 (99\% CI 66.12 to 71.37$)$ for contraindication, and 2.68 (99\% CI 2.63 to 2.74 ), 4.02 (99\% CI 3.91 to 4.13 ) and 5.17 (99\% CI 5.00 to 5.35) for informed dissent. Results for each QOF year and deprivation-both at practice and patient level-broadly agreed with models using individual conditions. However, we observed higher exception reporting odds for men on both contraindication $(\mathrm{OR}=1.40,99 \% \mathrm{CI} 1.37$ to 1.44$)$ and informed dissent exemptions (OR=1.53, 99\% CI 1.49 to 1.56$)$.

\section{Exception reporting and survival in the following year}

Findings were broadly similar across analyses of CPRD or ONS verified deaths, so, we discuss the results for the latter only. Patients with one or more informed dissent codes recorded had a $20 \%$ higher risk of death in the following year, compared with patients who were not exception reported (HR 1.20, 99\% CI 1.17 to 1.24). The risk was higher for clinical contraindication and for patients exempted from the whole domain (for whom a specific reason for exemption is not available), with HRs of 1.37 (99\% CI 1.33 to 1.40 ) and 1.39 (99\% CI 1.22 to 1.58 ), respectively (table 3$)$. Men ( $\mathrm{HR}=1.28$, 99\% CI 1.25 to 1.31$)$ and smokers $(\mathrm{HR}=1.61,99 \% \mathrm{CI} 1.55$ to 1.66) had higher hazards of death. Area deprivation measured at the practice location did not predict mortality but deprivation at the patient location did; patients living in the most deprived quintile of areas had a higher risk of death $(\mathrm{HR}=1.32,99 \%$ CI 1.27 to 1.37), compared with patients living in the most affluent quintile of areas. Interpretation of the condition coefficients is not straightforward due to potential collinearity and the inclusion of time-varying covariates.

In alternative models where we pooled all types of exception reports into a single predictor, patients with at least one exception code had a $38 \%$ higher risk of death in the following year $(\mathrm{HR}=1.38,99 \%$ CI 1.35 to 1.41), compared with patients without a recorded exception report (see online supplementary appendix table A6). Under the propensity score controlled sensitivity analyses, the associations were even stronger. The HR was 1.63 (99\% CI 1.59 to 1.66 ) for any exemption, 1.67 (99\% CI: 1.63 to 1.71) for at least one clinical contraindication exemption and 1.35 (99\% CI 1.31 to 1.39 ) for at least one informed dissent exemption.

\section{Rates of met and unmet exemptions}

Rates of 'met' exemptions in the diabetes domain varied from $1.0 \%$ for treatment of microalbuminuria (ie, $1.0 \%$ of patients with diabetes with 
Table 2 Predictors of exception reporting (at least one exception code within each year and patient); logistic regression analyses on ONS linked data from 357 practices

\begin{tabular}{|c|c|c|c|}
\hline & \multicolumn{3}{|l|}{ OR $(99 \% \mathrm{Cl})$} \\
\hline & All reasons* $†$ & Clinical contraindication & Informed dissent§ \\
\hline \multicolumn{4}{|l|}{ QOF year } \\
\hline $2006 / 2007$ & Reference & Reference & Reference \\
\hline $2007 / 2008$ & 1.03 (1.02 to 1.05$)$ & $0.93(0.91$ to 0.95$)$ & $1.14(1.12$ to 1.16$)$ \\
\hline $2008 / 2009$ & $0.99(0.97$ to 1.00$)$ & $0.91(0.90$ to 0.93$)$ & $1.08(1.06$ to 1.10$)$ \\
\hline $2009 / 2010$ & 1.09 (1.08 to 1.11$)$ & 1.021 (1.00 to 1.04$)$ & $1.18(1.16$ to 1.21$)$ \\
\hline $2010 / 2011$ & 1.30 (1.28 to 1.32$)$ & 1.15 (1.12 to 1.17$)$ & $1.44(1.41$ to 1.47$)$ \\
\hline $2011 / 2012$ & $1.27(1.24$ to 1.29$)$ & 1.15 (1.13 to 1.18$)$ & $1.34(1.32$ to 1.37$)$ \\
\hline \multicolumn{4}{|l|}{ List size } \\
\hline Per 1000 increase & $1.01(1.01$ to 1.01$)$ & $1.00(0.99$ to 1.00$)$ & $1.02(1.02$ to 1.03$)$ \\
\hline \multicolumn{4}{|l|}{ English region } \\
\hline North East & Reference & Reference & Reference \\
\hline North West & 1.01 (0.95 to 1.08$)$ & 1.58 (1.45 to 1.72$)$ & $0.70(0.65$ to 0.74$)$ \\
\hline Yorkshire and The Humber & 0.62 (0.58 to 0.67$)$ & $0.93(0.85$ to 1.03$)$ & $0.51(0.47$ to 0.55$)$ \\
\hline East Midlands & 1.10 (1.02 to 1.19$)$ & 1.55 (1.40 to 1.72$)$ & $0.87(0.81$ to 0.95$)$ \\
\hline West Midlands & $0.66(0.62$ to 0.70$)$ & 1.04 (0.95 to 1.13$)$ & $0.47(0.44$ to 0.50$)$ \\
\hline East of England & $1.06(0.99$ to 1.13$)$ & 1.95 (1.79 to 2.13$)$ & $0.61(0.57$ to 0.65$)$ \\
\hline South West & 1.07 (1.00 to 1.14$)$ & 1.88 (1.72 to 2.05$)$ & $0.65(0.61$ to 0.69$)$ \\
\hline South Central & $0.84(0.78$ to 0.89$)$ & 1.27 (1.16 to 1.39$)$ & $0.62(0.57$ to 0.66$)$ \\
\hline London & $0.64(0.60$ to 0.68$)$ & 0.94 (0.86 to 1.03$)$ & $0.52(0.48$ to 0.55$)$ \\
\hline South East Coast & $0.68(0.63$ to 0.73$)$ & $0.96(0.88$ to 1.05$)$ & $0.57(0.54$ to 0.61$)$ \\
\hline \multicolumn{4}{|l|}{ Practice deprivation quintile } \\
\hline 1 (least deprived) & Reference & Reference & Reference \\
\hline 2 & $1.31(1.27$ to 1.36$)$ & 1.62 (1.56 to 1.69$)$ & 1.04 (1.00 to 1.07$)$ \\
\hline 3 & $1.55(1.50$ to 1.61$)$ & 1.84 (1.76 to 1.92$)$ & $1.17(1.13$ to 1.22$)$ \\
\hline 4 & $1.28(1.24$ to 1.33$)$ & 1.51 (1.44 to 1.57$)$ & 1.04 (1.01 to 1.08$)$ \\
\hline 5 & 1.33 (1.28 to 1.38$)$ & $1.40(1.34$ to 1.47$)$ & $1.19(1.15$ to 1.24$)$ \\
\hline \multicolumn{4}{|l|}{ Gender } \\
\hline Female & Reference & Reference & Reference \\
\hline Male & 1.01 (0.99 to 1.03$)$ & 0.90 (0.88 to 0.92$)$ & $1.08(1.06$ to 1.10$)$ \\
\hline \multicolumn{4}{|l|}{ Age } \\
\hline Per 1-year increase & $1.02(1.02$ to 1.03$)$ & 1.04 (1.03 to 1.04$)$ & 1.02 (1.01 to 1.02$)$ \\
\hline \multicolumn{4}{|l|}{ Patient deprivation quintile } \\
\hline 1 (least deprived) & Reference & Reference & Reference \\
\hline 2 & 1.06 (1.03 to 1.09$)$ & $1.12(1.08$ to 1.16$)$ & $1.00(0.97$ to 1.03$)$ \\
\hline 3 & 1.10 (1.07 to 1.13$)$ & 1.10 (1.06 to 1.15$)$ & $1.10(1.06$ to 1.13$)$ \\
\hline 4 & 1.15 (1.11 to 1.19$)$ & 1.14 (1.10 to 1.19$)$ & $1.16(1.12$ to 1.20$)$ \\
\hline 5 & $1.16(1.12$ to 1.20$)$ & 1.29 (1.24 to 1.35$)$ & 1.07 (1.03 to 1.12$)$ \\
\hline \multicolumn{4}{|l|}{ Conditions $\mathbb{9}$} \\
\hline Atrial fibrillation & 3.11 (3.00 to 3.22 ) & 5.33 (5.11 to 5.56$)$ & $1.06(1.02$ to 1.11$)$ \\
\hline Asthma & 4.97 (4.86 to 5.09 ) & 2.85 (2.77 to 2.93$)$ & 4.58 (4.47 to 4.69$)$ \\
\hline Hypertension & 1.47 (1.44 to 1.50$)$ & $1.71(1.67$ to 1.76$)$ & 1.15 (1.13 to 1.18$)$ \\
\hline Cancer & 0.96 (0.93 to 0.99$)$ & 1.18 (1.14 to 1.22$)$ & 0.80 (0.78 to 0.83$)$ \\
\hline Coronary heart disease & $9.82(9.54$ to 10.11$)$ & 23.71 (22.87 to 24.58$)$ & $2.20(2.14$ to 2.27$)$ \\
\hline Heart failure & 1.83 (1.74 to 1.92$)$ & 2.54 (2.40 to 2.70$)$ & 0.98 (0.93 to 1.03$)$ \\
\hline Chronic kidney disease & $1.82(1.78$ to 1.87$)$ & 2.43 (2.36 to 2.51$)$ & $1.08(1.05$ to 1.11$)$ \\
\hline COPD & 5.84 (5.63 to 6.07$)$ & 9.20 (8.78 to 9.64$)$ & 2.24 (2.15 to 2.33$)$ \\
\hline Dementia & 2.24 (2.13 to 2.37$)$ & 3.25 (3.04 to 3.46$)$ & 1.02 (0.96 to 1.09$)$ \\
\hline Depression & $0.94(0.92$ to 0.96$)$ & 1.81 (1.76 to 1.85$)$ & $0.52(0.51$ to 0.53$)$ \\
\hline Diabetes mellitus & 6.35 (6.20 to 6.51$)$ & 5.06 (4.91 to 5.22$)$ & 5.38 (5.25 to 5.52$)$ \\
\hline Epilepsy & $5.30(5.01$ to 5.60$)$ & $11.76(11.00$ to 12.59$)$ & 1.37 (1.29 to 1.47$)$ \\
\hline
\end{tabular}




\begin{tabular}{|c|c|c|c|}
\hline & \multicolumn{3}{|l|}{ OR $(99 \% \mathrm{Cl})$} \\
\hline & All reasons* $†$ & Clinical contraindication‡ & Informed dissent§ \\
\hline Learning disability & $1.10(1.00$ to 1.22$)$ & 1.75 (1.54 to 1.99$)$ & $0.66(0.58$ to 0.75$)$ \\
\hline Severe mental illness & 4.38 (4.17 to 4.60$)$ & $4.42(4.15$ to 4.70$)$ & 2.83 (2.68 to 2.98$)$ \\
\hline Stroke & 3.61 (3.48 to 3.73$)$ & 3.84 (3.68 to 4.01$)$ & 2.44 (2.35 to 2.53$)$ \\
\hline Hypothyroidism & $0.87(0.84$ to 0.90$)$ & $0.93(0.89$ to 0.96$)$ & $0.84(0.81$ to 0.87$)$ \\
\hline
\end{tabular}

${ }^{*}$ Clinical contraindication, informed dissent or reason unknown. Logistical exceptions were not included in analyses.

†No of observations=5 787456 , No of subjects=1 414 897, Log likelihood=-1 869483 , Wald $\chi^{2}=224393$.

$\ddagger$ No of observations $=5787456$, No of subjects $=1414897$, Log likelihood $=-1211443$, Wald $\chi^{2}=223723$.

$\S$ No of observations $=5787$ 456, No of subjects=1 414 897, Log likelihood=-1 249 265, Wald $\chi^{2}=87458$.

१Reference: patients without the specific condition, but with one or more other study conditions.

COPD, chronic obstructive pulmonary disease; ONS, Office of National Statistics; QOF, Quality and Outcomes Framework.

microalbuminuria were both exempted for this indicator and received treatment) to $7.1 \%$ for control of $\mathrm{HbA} 1 \mathrm{c} \leq 10 \%$ (figure 2 and appendix figure A1). On average across the whole study period, quality standards were met for $48 \%$ of exempted patients, but this varied across indicators from $8 \%$ for the treatment of microalbuminuria (ie, $8 \%$ of patients exempted for this indicator were nevertheless treated) to $80 \%$ for the measurement of blood pressure (details on the indicators are provided in online supplementary appendix table A3). For simple processes such as blood pressure measurement or blood tests, the majority of exempted patients eventually received the incentivised care. Conversely, for more complex processes such as retinal screening and for treatments, only a minority received the incentivised care.

For the intermediate outcomes indicators, targets were achieved for the majority of exempted patients, with the exception of the indicator relating to tight glycaemic control (HbA1c $\leq 7.0 / 7.5 \%)$, for which only $29 \%$ of exceptions were met, compared with $60 \%$ for moderate glycaemic control (HbA1c $\leq 9.0$ / $10.0 \%)$. Since the intermediate outcome indicators cannot be met without first meeting the respective process indicator (eg, the patient automatically fails the blood pressure control indicator if blood pressure is not measured), a proportion of patients who are eventually measured will therefore meet the intermediate outcome indicator without the practice changing their treatment.

\section{DISCUSSION}

Tailoring population-based guidelines to the needs and preferences of individual patients can be challenging, both for designers of guidelines and for clinicians applying them in practice. This challenge is further complicated in the context of pay-for-performance programmes: when clinicians are financially incentivised to apply guidelines, the risk of inappropriate care increases. The provision for practices to exception report patients under the UK's QOF is intended to obviate this risk and ensure shared decision making in the consultation process, ${ }^{32-34}$ at a relatively low cost. ${ }^{14}$ However, it may in turn result in patients who would benefit from inclusion in the quality scheme being inappropriately excluded. National guidance on exception reporting states that exempted patients should 'still be the recipients of best clinical care and practice'. ${ }^{23}$ We found that quality standards are subsequently met for almost half of exempted patients. We also found that certain patient groups are more likely to be exempted, and that exempted patients have poorer outcomes. However, patients who are already in poor health are more likely to be exempted or to refuse treatments, and the complex relationships between exception reporting, health status and patient outcomes will require further investigation.

\section{Limitations}

First, this is an analysis of observational data and it is difficult to demonstrate causality, or even directionality in some cases. For example, while non-provision of recommended care may lead to poorer health outcomes and increase the risk of mortality, patients who are already in very poor health may also be more likely to refuse treatment and investigations. Even so, the relationship between informed dissent and mortality persisted after controlling for morbidities and other types of exceptions. Second, although our modelling approach attempted to replicate as closely as possible the processes by which exceptions are applied by practices, we cannot directly compare rates reported under the national QOF scheme and those we calculated using CPRD data. We used more inclusive code lists than what are used under the QOF rules, to better account for changes in recording practice and in the rules themselves over time. ${ }^{72}$ Levels of exception reporting also varied across geographical areas. Although our CPRD sample was broadly nationally representative, some regions were overrepresented and others were under-represented. ${ }^{27}$ Third, CPRD collects data from practices that use a single computer system (Vision) and differences in recording routines might exist across clinical computer systems. ${ }^{24}$ Fourth, reasons for exception reporting are not mutually exclusive, and we cannot assume that 
Table 3 Exception reporting, by reason, ${ }^{*}$ as a predictor of survival in the subsequent year; proportional-hazards survival analyses on ONS linked data from 357 practices

\begin{tabular}{|c|c|}
\hline & HR $(95 \% \mathrm{Cl}) \dagger$ \\
\hline \multicolumn{2}{|l|}{ Exception reported‡ } \\
\hline Clinical contraindication & $1.37(1.33$ to 1.40$)$ \\
\hline Informed dissent & 1.20 (1.17 to 1.24$)$ \\
\hline Unknown reason & 1.39 (1.22 to 1.58$)$ \\
\hline Age§ & 1.07 (1.05 to 1.09$)$ \\
\hline \multicolumn{2}{|l|}{ Gender } \\
\hline Female & Reference \\
\hline Male & $1.28(1.25$ to 1.31$)$ \\
\hline \multicolumn{2}{|l|}{ Smoking status } \\
\hline Never smoked & Reference \\
\hline Ex-smoker & 0.97 (0.95 to 0.995) \\
\hline Current smoker & 1.61 (1.55 to 1.66$)$ \\
\hline Missing§ & $8.71(1.23$ to 61.63$)$ \\
\hline \multicolumn{2}{|l|}{ Patient deprivation quintile } \\
\hline 1 (least deprived) & Reference \\
\hline 2 & $1.06(1.03$ to 1.10$)$ \\
\hline 3 & $1.12(1.09$ to 1.16$)$ \\
\hline 4 & $1.20(1.17$ to 1.25$)$ \\
\hline 5 & $1.32(1.27$ to 1.37$)$ \\
\hline Practice list size (1000 s) & 1.000 (0.999 to 1.002$)$ \\
\hline \multicolumn{2}{|l|}{ Practice deprivation quintile } \\
\hline 1 (least deprived) & Reference \\
\hline 2 & 0.99 (0.96 to 1.02$)$ \\
\hline 3 & $0.98(0.94$ to 1.01$)$ \\
\hline 4 & 0.99 (0.95 to 1.02$)$ \\
\hline 5 & 1.03 (0.99 to 1.07$)$ \\
\hline \multicolumn{2}{|l|}{ Conditions } \\
\hline Atrial fibrillation & $1.32(1.29$ to 1.36$)$ \\
\hline Asthma & 0.91 (0.88 to 0.94$)$ \\
\hline Hypertension & 0.90 (0.88 to 0.92$)$ \\
\hline Cancer§ & 1.60 (1.11 to 2.31$)$ \\
\hline Coronary heart disease & 0.97 (0.95 to 0.997$)$ \\
\hline Heart failure & $1.68(1.62$ to 1.73$)$ \\
\hline Chronic kidney disease§ & $1.60(1.13$ to 2.27$)$ \\
\hline Chronic obstructive pulmonary disease & $1.72(1.67$ to 1.77$)$ \\
\hline Dementia§ & $3.07(1.85$ to 5.11$)$ \\
\hline Depression & $1.06(1.03$ to 1.08$)$ \\
\hline Diabetes mellitus§ & 1.39 (0.94 to 2.06$)$ \\
\hline Epilepsy & $1.68(1.58$ to 1.80$)$ \\
\hline Learning disability§ & 8.85 (0.33 to 234.09$)$ \\
\hline Severe mental illness & $1.43(1.35$ to 1.51$)$ \\
\hline Stroke & $1.32(1.29$ to 1.36$)$ \\
\hline Hypothyroidism & 0.99 (0.96 to 1.02$)$ \\
\hline \multicolumn{2}{|l|}{ Time-varying $(\times \log (t))$} \\
\hline Age & $1.01(1.00$ to 1.01$)$ \\
\hline Smoking status: missing & $0.34(0.13$ to 0.88$)$ \\
\hline Cancer & $1.21(1.01$ to 1.43$)$ \\
\hline Chronic kidney disease & $0.87(0.74$ to 1.03$)$ \\
\hline Dementia & $0.89(0.70$ to 1.14$)$ \\
\hline Diabetes mellitus & $0.94(0.78$ to 1.13$)$ \\
\hline Learning disability & $0.53(0.11$ to 2.67$)$ \\
\hline
\end{tabular}

Based on ONS deaths. Number of observations $/$ time at risk=4416374, Number of subjects=1194389 (excluding data for 2011/12 since survival information for the following year was not available), Number of failures $=68756$, Log pseudolikelihood $=-869469$, Wald Chi2 $=120783$.

${ }^{*}$ Clinical contraindication, informed dissent or reason unknown. Logistical exceptions were not included in analyses.

tBased on ONS deaths. No of observations/time at risk=4 416374 , No of subjects=1 194389 , No of failures $=68756$, Log pseudolikelihood $=-869469$, Wald $\chi^{2}=120783$.

$\ddagger$ At least one code within each category.

§Interpretation of the HRs for these covariates is not straightforward because of the inclusion of the time-varying components.

ONS, Office of National Statistics. patients giving informed dissent do not also have a contraindication, although a practice would not need to obtain a reason for dissent if a contraindication was recorded. Fifth, analyses of primary care databases rest on the assumption that GPs accurately record consultations in their clinical computer systems, and for the purposes of this study that, for example, informed dissent exemptions are recorded as such. Although we cannot be certain this is the case, the very low usage of generic codes is an indication that practices have sought to record the reason for exception reporting. Sixth, overall mortality may not be a sensitive enough measure and cause-specific mortality for each condition of interest linked to exceptions from specific relevant indicators, although answering a slightly different research question, could potentially provide a more informative clinical picture. Finally, although we used all QOF conditions to define our cohort (which include all major conditions), most conditions are not included in QOF and our analyses therefore investigate the relationship between QOF-specific multimorbidity and outcomes.

\section{Findings}

The likelihood of being exception reported under the pay-for-performance scheme varied with patient characteristics. In the regression models, older people, women and patients in less affluent areas were more likely to be exception reported for a clinical contraindication. This broadly agrees with previous findings for patients with diabetes in North West London. ${ }^{21}$ Patterns were similar for informed dissent, but men were more likely to be exception reported than women. The higher overall raw rates of exception reporting in men are largely attributable to higher prevalence of conditions such as coronary heart disease and diabetes. ${ }^{35}{ }^{36}$ Patients with these conditions were more likely to have one or more exception reports, as were patients with chronic obstructive pulmonary disease or epilepsy. The probability of being exempted increased sharply with the number of chronic conditions: compared with patients with a single condition, patients with two conditions were four times more likely to be exempted for a contraindication and patients with four or more conditions were almost 70 times more likely. This finding was expected, as the presence of a supervening condition or extreme frailty are the criteria for exemption. However, we also found that multimorbid patients were more likely to refuse monitoring and treatment under the scheme. This raises questions about the appropriateness of incentive frameworks and guidelines based on single conditions. ${ }^{37}$

Greater area deprivation was also associated with higher exception rates. In our results, this is mainly driven by clinical contraindication exemptions and to a smaller extent by refusal of treatment. It seems 


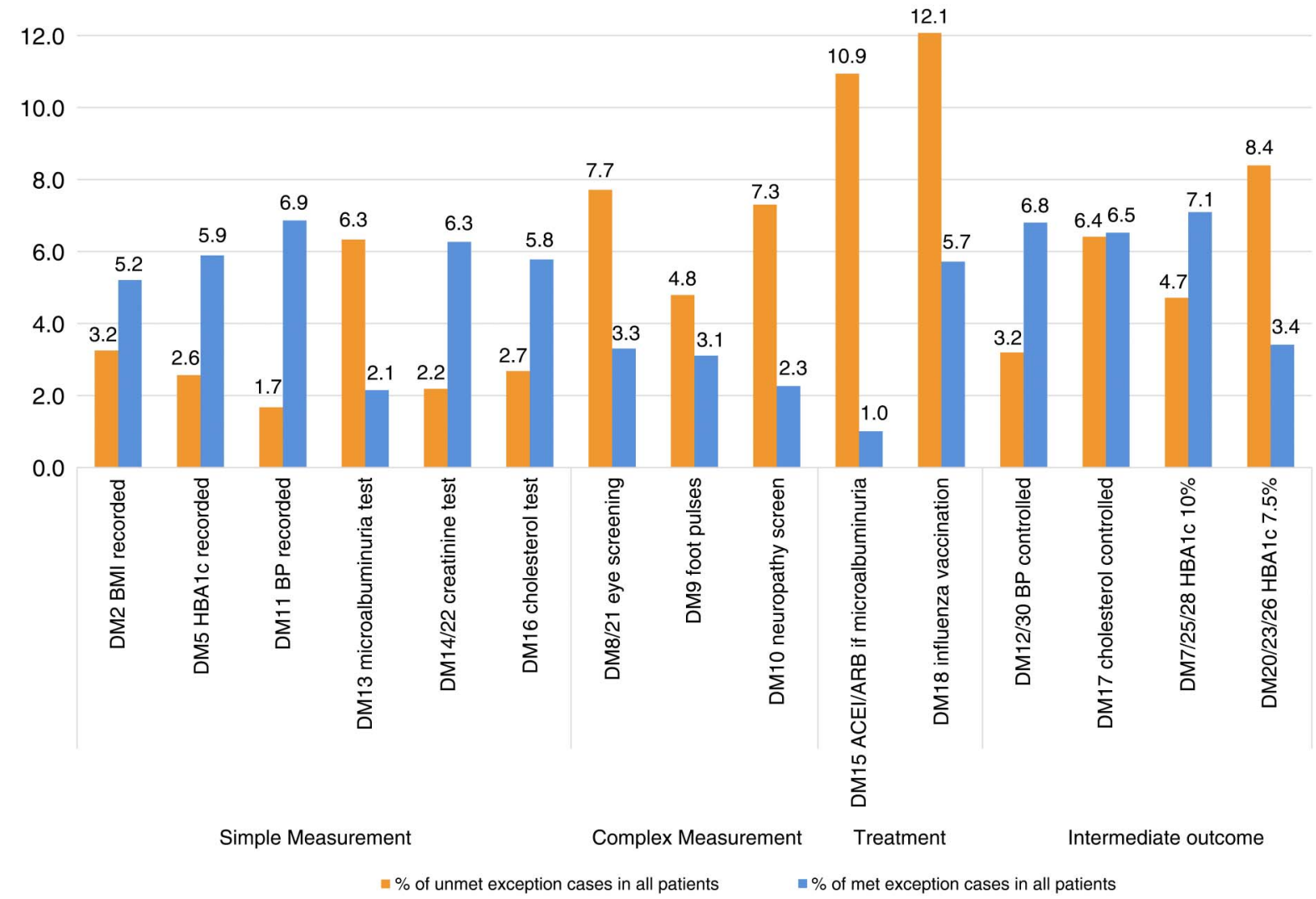

Figure 2 Exception reporting rates in the diabetes domain of the Quality and Outcomes Framework (QOF), aggregated over time. *Details on the indicators are provided in online supplementary appendix table A3. +DM9 changes significantly in $2011 / 2012$ so calculations for that indicator are limited to 2006/2007-2010/2011. ‡Patients with documented proteinuria are exempted for indicator DM13.

likely that the poorer health of patients residing in more deprived areas leads to more contraindication exceptions, although refusal is also a factor, possibly driven by health experiences, education or other aspects of deprivation that are captured in the index of multiple deprivation. However, we observed a stronger (and a non-linear) relationship between exception reporting and area deprivation measured at the practice location than at the patient location, especially for contraindications, with the highest rates observed for the middle deprivation quintile. This suggests that exception reporting usage varies with practice location deprivation, above what would be expected from the average deprivation of the practice population. A possible explanation for the non-linear nature of the effect is that patients are more likely to be undiagnosed in the most deprived practices, and hence less likely to be exception reported due to contraindication. Alternatively, practices in the most deprived areas might be performing well in terms of case finding, but might not use contraindication exception reports as much as practices in more affluent areas. In either case, it is possible that recording of exceptions is less complete in practices located in the most deprived areas.
With respect to mortality, we observed several wellknown relationships: men, smokers, patients residing in more deprived areas and multimorbid patients had a higher probability of dying. Controlling for these factors, we found that patients receiving one or more exception codes, of any type, were more likely to die the following year. Compared with patients with no exceptions, mortality rates were the highest for contraindication exceptions ( $\approx 37 \%$ higher) and also significantly higher for informed dissent exceptions $(\approx 20 \%$ higher). For contraindication exception reporting, we can reasonably assume that the relationship with mortality is confounded by multimorbidity and overall health: less healthy patients are more likely to have a contraindication, intolerance or terminal illness.

Similar confounding is also likely to occur for informed dissent, but the strength of the confounding is likely to be weaker (multimorbidity, a reasonable proxy for overall health, was a weaker predictor of informed dissent than of contraindications). However, in the survival analyses we controlled for all major conditions and also used propensity scores as an alternative way to control for confounders of the effect of informed dissent on mortality and the effect persisted. Although there is a risk of unmeasured confounding 
(eg, multimorbidity not captured by the QOF conditions), it does appear that refusal of QOF investigations and treatments is linked to poorer outcomes. However, previous investigations have questioned the effectiveness of some QOF indicators ${ }^{36}$ and have failed to identify a link between performance on QOF indicators and mortality. ${ }^{12}$ Therefore, although informed dissent under the QOF might have no direct effect on survival, it might be a proxy for non-adherence with the advice and recommendations of health professionals generally, or of other risk-prone or unhealthy behaviours. ${ }^{38}$ Informed dissent potentially identifies a group of patients for whom it would be appropriate to design and evaluate more tailored interventions to optimise care according to their preferences.

Finally, within the diabetes indicator set, we saw that the levels of 'met' exception reporting are not negligible and are high for some indicators, indicating that the exception reporting provision is used more often than previously reported under the QOF scheme. For example, for indicators relating to blood pressure measurement and control, 'met' exemption rates were higher than the 'unmet' rates reported under the QOF. This finding is in agreement with previous work that reported high met exemption rates for influenza immunisation. ${ }^{27}$ The high observed met exception reporting rates for most indicators suggests that health professionals are often successful in delivering incentivised care to patients who were initially exempted, whether for reasons of contraindication or informed dissent. This appears to be more likely to occur for more straightforward measurement activities (eg, blood pressure measurement), which are easier to deliver if the patient attends for routine care, compared with more complex activities and interventions (eg, diabetic eye screening). Similarly, there were more met exceptions for the less challenging of the two glycaemic control targets.

\section{CONCLUSIONS}

Older, male, more multimorbid and more socioeconomically deprived patients are more likely to be exempted from the UK's QOF. Furthermore, patients who are exception reported are more likely to die in the following year, whether they were exempted by the practice for a contraindication or by themselves through informed dissent. In most cases, this may be entirely appropriate, as an exemption will often be an indication of the practice recognising the limitations imposed by existing poor health or respecting the wishes of frail patients in a shared decision-making process. ${ }^{14}{ }^{34}$ It appears that the exception reporting provisions in the scheme are generally being used properly by practices to tailor national guidelines to individual patients' circumstances and preferences. ${ }^{39}$ However, the greater use of exception reporting in particular patient groups raises questions about whether the QOF is contributing to healthcare inequalities, with practices serving such patients using exception reporting, legitimately or otherwise, in response to difficulties in engaging patients who are less able or willing to attend routine chronic disease clinics. ${ }^{20}$ The QOF payment system makes no allowance for differences in the work required to deliver care to different patient groups. Similarly, the association between informed dissent exception reporting and higher mortality again highlights that there may be opportunities for more tailored approaches for groups of patients for whom the one-size-fits-all approach of QOF sits uncomfortably. There are lessons here for designers of other incentive schemes, who must balance the requirement for consistent targets with the need to include mechanisms that allow for the exercise of discretion by clinicians and autonomy by patients. Further explorations of the relationships between the exact reasons for exception reporting and cause-specific mortality are needed to ensure that patients are receiving the optimum benefit from incentivisation interventions.

\section{Author affiliations}

${ }^{1}$ NIHR School for Primary Care Research, Centre for Primary Care, Institute of Population Health, University of Manchester, Manchester, UK

${ }^{2}$ Centre for Health Informatics, Institute of Population Health, University of Manchester, Manchester, UK

${ }^{3}$ Centre for Biostatistics, Institute of Population Health, University of Manchester, Manchester, UK

${ }^{4}$ Centre for Pharmacoepidemiology and Drug Safety, Manchester Pharmacy School, University of Manchester, Manchester, Uk

${ }^{5}$ Patient Centred Care, APEx Collaboration for Academic Primary Care, Medical School, University of Exeter, Exeter, UK ${ }^{6}$ Population Health Sciences Division, Medical Research Institute, University of Dundee, Dundee, Uk

${ }^{7}$ Department of Health Sciences, University of York, York, UK

Twitter Follow Tim Doran at @narodmit and Evangelos Kontopantelis at@dataevan

Contributors EK and TD designed the study. DAS extracted the data. EK performed the statistical analyses. EK and TD wrote the manuscript. DR, DAS, DMA, BG, JMV and SNvdV were involved in interpreting the findings and editing the manuscript. EK is the guarantor of this work and, as such, had full access to all the data in the study and takes responsibility for the integrity of the data and the accuracy of the data analysis.

Funding NIHR School for Primary Care Research (Project \#141); Medical Research Council; Health eResearch Centre grant MR/K006665/1.

Competing interests EK was partly supported by a NIHR School for Primary Care Research fellowship in primary healthcare; TD was supported by a NIHR Career Development Fellowship.

Ethics approval ISAC approval, protocol 12_147Ra.

Provenance and peer review Not commissioned; externally peer reviewed.

Data sharing statement Clinical Practice Research Datalink data cannot be shared due to licensing restrictions.

Open Access This is an Open Access article distributed in accordance with the Creative Commons Attribution Non Commercial (CC BY-NC 4.0) license, which permits others to distribute, remix, adapt, build upon this work non-commercially, and license their derivative works on different terms, provided the original work is properly cited and the use is non-commercial. See: http://creativecommons.org/licenses/by-nc/4.0/ 


\section{REFERENCES}

1 Roland M. Linking physicians' pay to the quality of care-a major experiment in the United Kingdom. $N$ Engl J Med 2004;351:1448-54.

2 Centers for Medicare \& Medicaid Services (CMS), HHS. Medicare program; hospital inpatient value-based purchasing program. Final rule. Fed Regist 2011;76:26490-547.

3 Centers for Medicare \& Medicaid Services (CMS), HHS. Medicare program; hospital inpatient prospective payment systems for acute care hospitals and the long-term care hospital prospective payment system and fiscal year 2015 rates; quality reporting requirements for specific providers; reasonable compensation equivalents for physician services in excluded hospitals and certain teaching hospitals; provider administrative appeals and judicial review; enforcement provisions for organ transplant centers; and electronic health record (EHR) incentive program. Final rule. Fed Regist 2014;79:49853-50536.

4 Australia M. Practice incentives program. Sydney: Australian Government, 2011.

5 Campbell SM, Reeves D, Kontopantelis E, et al. Effects of pay for performance on the quality of primary care in England. N Engl J Med 2009;361:368-78.

6 Doran T, Kontopantelis E, Valderas JM, et al. Effect of financial incentives on incentivised and non-incentivised clinical activities: longitudinal analysis of data from the UK Quality and Outcomes Framework. BMJ 2011;342: d3590.

7 Kontopantelis E, Reeves D, Valderas JM, et al. Recorded quality of primary care for patients with diabetes in England before and after the introduction of a financial incentive scheme: a longitudinal observational study. BMJ Qual Saf 2013;22:53-64.

8 Dusheiko M, Doran T, Gravelle H, et al. Does higher quality of diabetes management in family practice reduce unplanned hospital admissions? Health Serv Res 2011;46:27-46.

9 Purdy S, Griffin T, Salisbury C, et al. Emergency respiratory admissions: influence of practice, population and hospital factors. J Health Serv Res Policy 2011;16:133-40.

10 Bottle A, Gnani S, Saxena S, et al. Association between quality of primary care and hospitalization for coronary heart disease in England: national cross-sectional study. J Gen Intern Med 2008;23:135-41.

11 Harrison MJ, Dusheiko M, Sutton M, et al. Effect of a national primary care pay for performance scheme on emergency hospital admissions for ambulatory care sensitive conditions: controlled longitudinal study. BMJ 2014;349: g6423.

12 Kontopantelis E, Springate DA, Ashworth M, et al. Investigating the relationship between quality of primary care and premature mortality in England: a spatial whole-population study. BMJ 2015;350:h904.

13 Flodgren G, Eccles MP, Shepperd S, et al. An overview of reviews evaluating the effectiveness of financial incentives in changing healthcare professional behaviours and patient outcomes. Cochrane Database Syst Rev 2011;(7): CD009255.

14 Doran T, Kontopantelis E, Fullwood C, et al. Exempting dissenting patients from pay for performance schemes: retrospective analysis of exception reporting in the UK Quality and Outcomes Framework. BMJ 2012; 344:e2405.
15 Doran T, Fullwood C, Gravelle H, et al. Pay-for-performance programs in family practices in the United Kingdom. $\mathrm{N} \mathrm{Engl} \mathrm{J}$ Med 2006;355:375-84.

16 Gravelle H, Sutton M, Ma A. Doctor behaviour under a pay for performance contract: treating, cheating and case finding? Econ J 2010;120:F129-56.

17 Doran T, Fullwood C, Reeves D, et al. Exclusion of patients from pay-for-performance targets by English physicians. N Engl J Med 2008;359:274-84.

18 Kontopantelis E, Doran T, Gravelle H, et al. Family doctor responses to changes in incentives for influenza immunization under the U.K. Quality and Outcomes Framework pay-for-performance scheme. Health Serv Res 2012;47:1117-36.

19 Pape U, Huckvale K, Car J, et al. Impact of 'stretch' targets for cardiovascular disease management within a local pay-for-performance programme. PLoS One 2015;10: e0119185.

20 Campbell S, Hannon K, Lester H. Exception reporting in the Quality and Outcomes Framework: views of practice staff-a qualitative study. Br J Gen Pract 2011;61:183-9.

21 Dalton AR, Alshamsan R, Majeed A, et al. Exclusion of patients from quality measurement of diabetes care in the UK pay-for-performance programme. Diabet Med 2011;28:525-31.

22 Prescribing and Primary Care Services HSCIC. Quality and Outcomes Framework-Prevalence, Achievements and Exceptions Report: England, 2013-14. Health \& Social Care Information Centre, 2014:63. http://www.hscic.gov.uk/ catalogue/PUB15751/qof-1314-report.pdf

23 NHS Employers. Quality and Outcomes Framework guidance for GMS contract 2013/14. NHS Employers, 2013. http://bma. org.uk/-/media/files/pdfs/practical\%20advice\%20at\%20work/ contracts/gpqofguidance20132014.pdf

24 Kontopantelis E, Buchan I, Reeves D, et al. Relationship between quality of care and choice of clinical computing system: retrospective analysis of family practice performance under the UK's quality and outcomes framework. BMJ Open 2013;3:e003190.

25 Communities and Local Government. The English indices of deprivation 2010. Technical Report. Government DfCaL, 2011. http://www.communities.gov.uk/documents/statistics/pdf/ 1870718.pdf

26 McLean G, Guthrie B, Watt G, et al. Practice postcode versus patient population: a comparison of data sources in England and Scotland. Int J Health Geogr 2008;7:37.

27 Kontopantelis E, Springate D, Reeves D, et al. Withdrawing performance indicators: retrospective analysis of general practice performance under UK Quality and Outcomes Framework. BMJ 2014;348:g330.

28 Springate DA, Kontopantelis E, Ashcroft DM, et al. ClinicalCodes: an online clinical codes repository to improve the validity and reproducibility of research using electronic medical records. PLoS One 2014;9:e99825.

29 R: a language and environment for statistical computing [program]. 3.1.1 version. R Foundation for Statistical Computing, 2013.

30 Stata Statistical software for Windows [program]. 13.1 version, 2013.

31 Lin MF, Lucas HC, Shmueli G. Too big to fail: large samples and the p-value problem. Inform Syst Res 2013;24:906-17. 


\section{Original research}

32 Elwyn G, Edwards A, Kinnersley P, et al. Shared decision making and the concept of equipoise: the competences of involving patients in healthcare choices. Br J Gen Pract 2000;50:892-9.

33 Stiggelbout AM, Van der Weijden T, De Wit MP, et al. Shared decision making: really putting patients at the centre of healthcare. BMJ 2012;344:e256.

34 Elwyn G, Frosch D, Thomson R, et al. Shared decision making: a model for clinical practice. J Gen Intern Med 2012; 27:1361-7.

35 O'Flaherty M, Ford E, Allender S, et al. Coronary heart disease trends in England and Wales from 1984 to 2004: concealed levelling of mortality rates among young adults. Heart 2008;94:178-81.
36 Kontopantelis E, Springate DA, Reeves D, et al. Glucose, blood pressure and cholesterol levels and their relationships to clinical outcomes in type 2 diabetes: a retrospective cohort study. Diabetologia 2015;58:505-18.

37 Hughes LD, McMurdo MET, Guthrie B. Guidelines for people not for diseases: the challenges of applying UK clinical guidelines to people with multimorbidity. Age Ageing 2013;42:62-9.

38 Curtis JR, Larson JC, Delzell E, et al. Placebo adherence, clinical outcomes, and mortality in the women's health initiative randomized hormone therapy trials. Med Care 2011;49:427-35.

39 Hopayian K. Exception reporting as a quality marker. Br J Gen Pract 2013;63:315-5. 